\title{
LIBERTAD DE EXPRESIÓN, REDES SOCIALES Y DERECHO PENAL ${ }^{1}$
}

\author{
FERNANDO MiRÓ LLINARES*
}

\section{I. ¿UN PAÍS CON MÁS O CON MENOS LIBERTAD DE EXPRESIÓN?}

No hace falta abrazar ningún tipo de escepticismo epistemológico para reconocer la dificultad que conlleva realizar cualquier afirmación, con pretensión de veracidad, referida al crecimiento o decrecimiento en la calidad del ejercicio de un hecho institucional-normativo tan aparentemente reconocible como complejo de plasmar como es la libertad de expresión. Y, sin embargo, no dejamos de hacerlo. Probablemente fruto de la tensión política que se vive en nuestro país, es común escuchar en los últimos tiempos manifestaciones relativas a la alta o baja calidad de nuestra democracia, en general, y en particular respecto a la buena o mala salud de la libertad de expresión, indiscutible pilar en la conformación y configuración real del ser democrático ${ }^{2}$. Y pese a que, más allá de la clara consolidación de la democracia en nuestro país, la popularización social de las redes sociales ha aumentado las posibilidades de expresarse libremente, por un lado incrementando las posibilidades de difusión y, por tanto, el impacto potencial de cualquier discurso, y, por otro, democratizando el mismo al ampliar a las redes sociales los canales de comunicación tradicional con la consiguiente superación de algunas de las

\footnotetext{
${ }^{1}$ Artículo realizado dentro del proyecto "Criminología, evidencias empíricas y Política criminal. Sobre la incorporación de datos científicos para la toma de decisiones en relación con la criminalización de conductas - Referencia: DER2017-86204-R, financiado por la (AEI)/MCIU y la Unión Europea a través del Fondo Europeo de Desarrollo Regional -FEDER- “Una manera de hacer Europa”. También gracias a las ayudas a las acciones de dinamización "Redes de Excelencia" proyecto: Desarrollo de un modelo criminológico y empírico de la política criminal -Acrónimo EmpiriC. Financiado por MCIU-AEI (Ref. DER2017-90552-REDT). Este trabajo es una versión comprimida y en español de un artículo titulado Miró-LlinARES, F., y GómeZ-BellVís, A. B., "Freedom of expression “\#minus2.0” in Spain? From the criminalization of hate speech to the privatization of censorship", en Spanish Journal of Legislative Studies, 2020, en prensa.

* Catedrático de Derecho Penal de la Universidad Miguel Hernández de Elche

${ }^{2}$ Véase en profundidad Presno Linera, M. Á., y Teruel LoZANo, G. M., La libertad de expresión en América y Europa, Editorial Juruá, Lisboa, 2017.
} 
limitaciones al acceso y difusión de medios ${ }^{3}$, lo cierto es que gran parte de las citadas declaraciones afirman la existencia de una involución y las que no van en tal sentido se expresan generalmente como defensa ante las primeras. Se dice que la libertad de expresión en España está en riesgo, que sufrimos una regresión en el ejercicio de este derecho e incluso que hay una persecución pública del disenso político que se manifiesta en la criminalización de ciertas formas de expresión pública.

Una primera reflexión, tan cierta como limitada, nos llevaría a afirmar que el que se diga todo esto resulta, en lenguaje coloquial, "una buena señal", en el sentido de que tales expresiones son posibles gracias al indiscutible marco general democrático en el que vivimos desde hace más de 40 años y en el que la libertad de expresión desempeña un papel fundamental. El mismo argumento podría entenderse reforzado por el hecho de que tales expresiones de diagnóstico de crisis de la libertad de expresión no provienen de un único sector ideológico sino de varios de ellos, en ocasiones incluso antagónicos (o al menos así se consideran unos y otros), y por motivos totalmente diferentes (unos quejándose de la dictadura de la unidad nacional, otros de la capitalista y otros de la "ideología de género"). De nuevo, no parece que la disidencia no pueda expresarse, ni que el Estado tenga una estrategia de ataque a una determinada ideología o a algún sector de la población. Pero también podríamos interpretar esta llamativa coincidencia entre sectores supuestamente irreconciliables como un indicador de que no estamos ante una crisis tradicional de la libertad de expresión que se dirima exclusivamente en los clásicos términos del eje democracia-totalitarismo, sino ante algo más complejo y profundo.

A mi parecer hay dos razones por las que creo que merece la pena reflexionar acerca de qué se puede afirmar respecto a la evolución de la libertad de expresión en España los últimos 25 años, y que son, además, las que van a determinar el enfoque de este trabajo. La primera es que, aunque las citadas afirmaciones generalmente no van acompañadas de ningún tipo de argumentación seria y objetiva que supere la mera referencia a un concreto supuesto de hecho interpretado parcialmente, hay excepciones,

\footnotetext{
${ }^{3}$ Así lo explica Teruel Lozano, G. M., "Libertades comunicativas y censura en el entorno tecnológico global", en Revista de la Escuela Jacobea de Posgrado, núm. 12, 2017, p. 81: "En relación en concreto con el uso de Internet y de las Nuevas Tecnologías, se proclama un (nuevo) derecho de acceso a la sociedad de la información y a las nuevas tecnologías de la información y la comunicación (TICs), incluso como derecho fundamental inherente al propio reconocimiento de la libertad de expresión y de información, necesario para participar en democracia".
} 
concretamente aquellas que incluyen referencias a indicadores con supuesta base empírica y que, como se verá, sí podrían indicar puntuales retrocesos. La segunda se refiere a que precisamente tales referencias empíricas que en general ponen el acento en diversos indicadores, éstos se fundamentan particularmente, en lo que a la evolución en España se refiere, en el papel que el sistema penal ha ido desempeñando en el sentido de convertirse en instrumento estatal de limitación de la libertad de expresión.

En efecto, con el apoyo de la ciencia política, la sociología y otras disciplinas vecinas desde hace décadas proliferan instrumentos que tratan de medir, sobre todo de forma comparada, la calidad democrática, o la libertad en los países. Y en este último aspecto es común la presencia, en la mayoría de ellos, y como indicador de la mayor o menor libertad, en general, y refiriéndose a la libertad de expresión en particular, de ítems relativos a la existencia de leyes penales y/o procesos judiciales derivados de ellas. Y resulta significativo que varios de los índices que miden el grado de libertad de expresión de diferentes Estados tengan en cuenta, a la hora de valorar su situación en España, el contexto legal y judicial de aplicación de los delitos de expresión, bien implícitamente al incluir indicadores referidos a estas cuestiones y realizar valoraciones de los mismos, o bien explícitamente refiriéndose de forma directa a la regulación penal y la interpretación por los tribunales de la misma como indicador de un retroceso en la libertad.

Del primer tipo es la evaluación que recibe España en The Human Freedom Index ${ }^{4}$, que sitúa a nuestro país en la posición 29 de entre 162 países $^{5}$, con una bajada de una posición en 2019 respecto al año anterior y una puntuación de 8.69 que se debe a la aplicación de índices diversos entre los que están el de "Leyes y normativa que influencia los medios", que en relación con los otros indicadores relativos a la libertad de expresión e información está comparativamente bajo y que ha evolucionado de una puntuación de 8.7 en 2011 hasta el 8.0 de 2019. Del segundo tipo, con referencia explícita a la regulación penal para valorar negativamente la evolución de la libertad de expresión

\footnotetext{
${ }^{4}$ El denominado Índice de Libertad en el Mundo, predecesor del índice de libertad humana, es un informe coeditado por el Instituto Cato, el Instituto Fraser y el Instituto Liberales de la Fundación Friedrich Naumann para la Libertad que se creó en 2015 y que analiza la libertad en 152 países sobre la base de casi ochenta indicadores distintos de libertad personal y económica.

${ }^{5}$ VÁsquez, I., y PoRnIK, T., The Human Freedom Index 2019. A Global Measurement of Personal, Civil and Economic Freedom, 2019. Disponible en: https://www.cato.org/sites/cato.org/files/human-freedomindex-files/2019-human-freedom-index-update-2.pdf. No es este el índice en el que mejor se sitúa nuestro país. En Europa occidental solo por encima de Italia y Francia y por debajo de otros 15 países.
} 
en España es la evaluación que hace Reporteros sin Fronteras en su informe de $2019^{6}$ y la de Freedom House ${ }^{7}$. En la primera, pese a que España pasa del puesto 31 al 29 con una subida de 1.48 puntos $^{8}$, el informe señala expresamente como problema el que "en 2018 se dictaron condenas por delitos como: hacer apología al terrorismo, insulto a la corona y ofensa "a los sentimientos de los miembros de una confesión religiosa", lo que creó un clima perjudicial para la libertad de información". Aún más significativa es la evaluación de la libertad de expresión, y la argumentación sobre la misma del que probablemente sea el índice más utilizado y conocido de los que miden y comparan la libertad y la democracia en general en los diferentes Estados y territorios, Freedom in The World ${ }^{9}$. El índice, elaborado por Freedom House en su informe de 2019 que otorga una puntuación global a España de 94 puntos sobre 100 y que la coloca en la posición 18 (junto a otros 8 países), atribuye un punto menos que en años anteriores a nuestro país en la categoría de Libertades Civiles, más concretamente en relación con la evolución de la libertad de expresión, y específicamente por el ítem D4 que analiza si “ ¿Son los individuos libres de expresar sus puntos de vista personales sobre temas políticos u otros temas sensibles sin temor a la vigilancia o al castigo?”. La razón que explícitamente usa Fredom House es la existencia de "un patrón de utilización de una ley antiterrorista ampliamente redactada y de otras disposiciones legales para enjuiciar a los individuos por sus expresiones políticas"; y añade que "la aplicación más agresiva de las leyes que prohíben la glorificación del terrorismo ha comenzado a amenazar la libertad de expresión, con docenas de personas, incluidos usuarios de redes sociales y varios artistas, declarados culpables en los últimos años por lo que, a menudo, equivale a la sátira, la expresión artística o el comentario político".

\footnotetext{
${ }^{6}$ Disponible en: https://www.informeanualrsf.es/

${ }^{7}$ Disponible en: https://freedomhouse.org/report-types/freedom-world

${ }^{8}$ Hay que tener en cuenta que la evolución de España en este índice desde 2013 es altamente positiva, pues en aquel año la posición que ocupaba era el puesto 36, habiendo llegado hasta el puesto 29 que se ocupó en 2017 y se ocupa de nuevo ahora.

${ }^{9}$ Algunos autores han criticado este índice por considerar que el mismo tiene un sesgo neoliberal que hace que puntúe más aquellos países con estrechos vínculos con EEUU o con instituciones políticas de corte similar (por ejemplo, GIANNONE, D., "Political and Ideological Aspects in the Measurement of Democracy: The Freedom House Case.", en Democratization, vol. 17, 2010; STEINER, N. D., "Comparing Freedom House Democracy Scores to Alternative Indices and Testing for Political Bias: Are US Allies Rated as More Democratic by Freedom House?", en Journal of Comparative Policy Analysis: Research and Practice, vol. 18, 2016. Sin embargo, BARNIDGe, M., HUber, B., DE ZÚÑIGA, H. G., y Liu, J. H., "Social Media as a Sphere for "Risky" Political Expression: A Twenty-Country Multilevel Comparative Analysis", en The International Journal of Press/Politics, vol. 23, 2018, matizan que si bien estos estudios muestran un sesgo neoliberal relativamente consistente en la medida antes de 1989, también muestran que los puntajes de Freedom House se alinean más estrechamente con otros índices de desempeño democrático después de ese tiempo.
} 
De nuevo, los datos existentes en los citados índices y en otros similares permitirían, en cuanto a la pregunta general que titula este epígrafe, tanto una visión optimista como otra más pesismista: parece válido tanto afirmar que, en comparación con otros países, España es un país esencialmente libre en el que las personas pueden expresarse generalmente $\sin$ temor $^{10}$, como decir que en los últimos años se detectan algunos indicios de regresión relacionados particularmente con la respuesta jurídicopenal a determinadas expresiones ofensivas en Internet. $\mathrm{Y}$ en la compatibilidad entre ambas visiones es donde a mi parecer se debe situar el punto de interés: más que ocuparnos en una absurda pelea de calificación general de la libertad de expresión en España resulta esencial comprender el papel que la legislación penal puede haber desempeñado en el ejercicio de la libertad. Pero, sobre todo, resulta fundamental saber cómo ha impactado la interpretación por los tribunales del Derecho penal desde que se popularizan las redes sociales como ámbito de expresión política por la ciudadanía. Al fin y al cabo, la mayoría de los casos de condenas y enjuiciamientos por delitos de expresión utilizados en los citados índices para valorar la puntuación en nuestro país, son de particulares realizando expresiones de tipo político en redes sociales. A todo ello hay que sumar que, además, hoy la censura ya no se ejerce exclusivamente desde el Estado, sino que también las propias redes sociales desempeñan un papel importantísimo en la decisión de qué opiniones se convierten en públicas y cuáles no ${ }^{11}$. Quizás tenga razón el índice Democracia 2017 cuando se preguntaba si la aparición de Internet ha supuesto “ ¿Una "edad de oro" o una "jaula dorada" para la libertad de expresión?”12 Es decir, ¿han aumentado las redes la libertad pero, a la vez, el control estatal sobre las mismas?, ¿cuál es el papel que el Estado, y en particular el Derecho penal, está desempeñando y debiera desempeñar?

\footnotetext{
${ }^{10}$ En esa línea también irían los datos de Democracy Index no hay indicadores directamente relacionados, sitúa a España no entre las 10 primeras, pero sí entre las 30 y como uno de los Estados que entran dentro de la categoría "fully democracies". Disponible en: https://infographics.economist.com/2020/democracyindex-2019/index.html

${ }^{11}$ Sobre ello véase en profundidad Teruel Lozano, G. M., "Libertades comunicativas y censura en el entorno tecnológico global", en Revista de la Escuela Jacobea de Posgrado, núm. 12, 2017.

12 Disponible en:

http://www.eiu.com/Handlers/WhitepaperHandler.ashx?fi=Democracy Index_2017.pdf\&mode=wp\&cam paignid=DemocracyIndex 2017
} 
La respuesta a estas preguntas requiere un análisis complejo del que aquí sólo se aborda una primera parte ${ }^{13}$. Un planteamiento analítico, donde el estudio empírico y el normativo se relacionen mucho más de lo que usualmente solemos hacer (tanto desde la disciplina jurídica como desde las ciencias sociales ${ }^{14}$ ), y que exige como primer paso el determinar cómo ha evolucionado el Derecho penal que afecta a la libertad de expresión y en particular si, como intuimos y de hecho ya se ha señalado en otros lugares ${ }^{15}$, la irrupción de las redes sociales ha supuesto un incremento en los supuestos enjuiciados y en la interpretación de los mismos. Esto es lo que se va a analizar en los puntos siguientes, como primera piedra desde la que determinar si de ello se puede derivar a su vez un impacto real en la libertad de expresión.

\section{EL IMPACTO DE LAS REDES SOCIALES EN EL TRATAMIENTO JUDICIAL DE LOS DELITOS DE EXPRESIÓN}

Señalé en otro lugar que al que se denominaba Derecho penal liberal le costaba sentirse cómodo con todo aquello que no tuviera una fisicidad evidente ${ }^{16}$. Así sucedía, y sucede, con los denominados delitos de expresión ${ }^{17}$, abundantes en nuestro Código Penal

\footnotetext{
${ }^{13}$ Un mayor desarrollo en Miró-LlinAREs, F., y GómEZ-Bellvís, A. B., "Freedom of expression...", ob. cit.

${ }^{14}$ Miró Llinares, F., “Cientismo, dogmatismo y Derecho penal”, en LH al Profesor Luzón Peña, en prensa; MiRó LlinARES, F., "Hechos en tierra de normas. Una introducción epistemológica a la relevancia de la realidad fáctica en el Derecho penal", en AA. VV., Estudios jurídico penales y criminológicos en homenaje al Prof. Dr. Dr. H. C. Mult. Lorenzo Morillas Cueva, Dykinson, Madrid, 2018.

15 Miró Llinares, F. (DIR.), Cometer delitos en 140 caracteres. El Derecho penal ante el odio y la radicalización en Internet, Marcial Pons, Madrid, 2017; MIRÓ LlinARES, F., "Ofender como acto de terrorismo. A propósito de los casos "César Strawberry" y "Cassandra Vera"”, en AA. VV., Liber amicorum. Estudios jurídicos en homenaje al profesor doctor Juan María Terradillos Vasoco, Tirant lo Blanch, Valencia, 2018; MIRÓ LLINARES, F., "La criminalización de conductas "ofensivas": A propósito del debate anglosajón sobre los "límites morales" del Derecho penal", en Revista Electrónica de Ciencia Penal y Criminología, núm. 17, 2015.

${ }^{16}$ Miró Llinares, F. (DIR.), Cometer delitos..., ob. cit., p. 15; Miró LlinARES, F., "Injuriar es ofender. Apuntes sobre la criminalización de los delitos contra el honor desde el enfoque teórico del daño/ofensa", en AA. VV., Libro homenale al profesor Dr. Agustín Jorge Barreiro, UAM Ediciones, Madrid, 2020.

${ }^{17}$ Esta denominación, delitos de expresión ha sido usualmente utilizada por la doctrina para referirse a los delitos de injurias y calumnias (CARMONA SALGADO, C., "Los delitos de expresión ante la reforma del proyecto de ley orgáncia de Código Penal de 1992", en AA. VV, Política Criminal y Reforma Penal. Homenaje a la memoria del Prof. Dr. D. Juan del Rosal, Editorial Revista de Derecho Privado, Madrid, 1993); también para referirse más ampliamente e incluir los delitos de odio o enaltecimiento del terrorismo (MIró Llinares, F. (DIR.), Cometer delitos en 140 caracteres..., ob. cit.), y también utilizada por el Grupo de estudios de Política criminal, que incluye los siguientes en su propuesta de reforma de los delitos de expresión: Injurias y calumnias en todas sus modalidades; los delitos de provocación al odio y al terrorismo; y las ofensas contra los sentimientos religiosos (AA. VV., Una propuesta alternativa de regulación de los delitos de expresión, Tirant lo Blanch, Valencia, 2019), aunque respecto de los últimos delitos, odio, enaltecimiento y ofensa a los sentimientos religiosos, también se les ha denominado delitos de opinión (Alastuey Dobón, C., "Discurso del odio y negacionismo en la reforma del Código Penal de 2015", en Revista Electrónica de Ciencia Penal y Criminología, RECPC 18-14, 201)
} 
y que han sido objeto de constantes críticas e interpretaciones restrictivas por parte de la doctrina $^{18}$ y han dado lugar a propuestas legislativas, normalmente de derogación o de modificación para la restricción de lo punible, conforme a la exigencia de la defensa de los derechos fundamentales en general y en particular del derecho a la libertad de expresión ${ }^{19}$. En sentido diverso ha ido, sin embargo, el legislador, que tanto en la reforma de la L.O. 7/2000, de 22 de diciembre, con la introducción del delito de enaltecimiento del terrorismo y humillación a sus víctimas como con la de la L.O. 1/2015, de 30 de marzo, con la ampliación del ámbito punitivo del denominado delito de odio ${ }^{20}$, ha ido ampliando los márgenes de lo punible y, podríamos afirmar intuitivamente, reduciendo los de la libertad de expresión.

Si nos fijamos simplemente en esto, en la evolución de la legislación penal en los últimos años, podríamos responder a la pregunta de si en España hay menos libertad de expresión, con un sí. Sin embargo, de dicha evolución legislativa no se puede derivar necesariamente un impacto real del Derecho en la práctica: podría haber sucedido que la interpretación judicial de los delitos haya dejado en nada la potencial ampliación punitiva; podría suceder simplemente que la ciudadanía no se haya sentido afectada por la conminación legal o por la noticia de su judicialización y haya seguido expresándose de igual forma. Hay que tener en cuenta, además, que el gran cambio social para la libertad de expresión en los últimos años no ha venido de ningún cambio legal sino de la popularización de las redes sociales que ha permitido que miles de personas se comuniquen a distancia y expresen sus ideas a otros. ¿Cómo ha impactado la generalización del uso de las redes sociales para la expresión libre de ideas con los delitos de expresión?, y, en particular, ¿ha supuesto esto un aumento en los casos enjuiciados y

\footnotetext{
${ }^{18}$ Miró Llinares, F. (DIR.), Cometer delitos..., ob. cit.

${ }^{19}$ La más reciente la del Grupo de Estudios de Política Criminal, Una propuesta alternativa de regulación de los delitos de expresión, Tirant lo Blanch, Valencia, 2019. En la misma línea el Informe elaborado por la Plataforma en defensa de la libertad de información junto con Acces Info Europe, la Federación de sindicatos de periodistas y el Grupo de Estudios de Política Criminal y Grupo de Investigación "Regulación jurídica y participación del ciudadano digital" de la Universidad Complutense de Madrid para su consideración en la 35 a sesión del Grupo de Trabajo del Consejo de Derechos Humanos de Naciones Unidas, donde abogan esencialmente por la despenalización de la mayor parte de los delitos de expresión. Disponible en: https://www.access-info.org/wp-content/uploads/EPU-Espa\%C3\%B1a-2019-informeFinal.pdf

${ }^{20}$ Sobre ello, RODRÍGUEZ FERRÁNDEZ, S., "El ámbito de aplicación del actual art. 510 CP en retrospectiva y en prospectiva tras la reforma penal de 2015", en Revista De Derecho Penal y Criminología, núm. 12, 2014; y sobre el odio véase en profundidad FUENTES OSORIO, J. L., "El odio como delito", en Revista Electrónica de Ciencia Penal y Criminología, núm. 19, 2017.
} 
en las condenas y absoluciones a los mismos tal y como señalan los índices anteriormente mencionados?

Para responder a estas cuestiones, aunque sea parcialmente, hemos llevado a cabo un análisis de resoluciones judiciales cuyos resultados esenciales, procedentes de otro trabajo, se expresan aquí de forma resumida ${ }^{21}$. Se han analizado un total de 217 sentencias localizadas en la base de datos de Aranzadi ${ }^{22}$ : 46 correspondientes a la aplicación del artículo 510; 150 del artículo 578; 15 de los artículos 490.3 y 491.1; y, 6 del artículo $525^{23}$. Así, gráficamente se puede observar la tendencia de aplicación judicial a lo largo de los años en el Gráfico $1^{24}$.

De una primera aproximación a este gráfico, cabe destacar que exceptuando el delito de enaltecimiento del terrorismo y humillación a sus víctimas del artículo $578 \mathrm{CP}$ $\mathrm{y}$, en menor medida, los delitos de odio del artículo $510 \mathrm{CP}$, el resto han tenido una aplicación más bien testimonial.

\footnotetext{
${ }^{21}$ Miró-LlinARES, F., y GóMEZ-Bellvís, A. B., "Freedom of expression...”, ob. Cit.

${ }^{22}$ Los criterios de inclusión han sido: por un lado, en cuanto a las disposiciones examinadas la L.O. 10/1995 de 23 de noviembre, y los artículos correspondientes aplicados desde el 23 de noviembre de 1995 hasta el 18 de febrero de 2020. Respecto del tipo de resolución se han aceptado únicamente las sentencias de procedimientos penales. De este modo y utilizando estos criterios por igual en los cuatro delitos analizados se han obtenido un total de 217 sentencias (tras eliminar de la muestra aquellas que estaban duplicadas o que bien, pese a los criterios de inclusión, no se correspondían con los delitos examinados). Así, cabe destacar que no se está afirmando en ningún caso que estas sean todas las sentencias que existan, dado que no disponemos de ese dato por medio de una base de datos como Aranzadi. No obstante, podemos tomar estos datos como un indicador o tendencia de las resoluciones judiciales, aunque siempre con la cautela que requiere un análisis exploratorio de este tipo.

${ }^{23}$ Sobre el delito de ofensa a los sentimientos religiosos véase en profundidad RAMOs VÁZQUEZ, J. A., "Muerte y resurrección del delito de escarnio en la jurisprudencia española", en Revista Electrónica de Ciencia Penal y Criminología, núm. 21, 2019.

${ }^{24}$ En relación con este gráfico, debe tomarse en cuenta que se han tenido en cuenta las resoluciones judiciales obtenidas de los criterios de inclusión y donde se incluyen las resoluciones de los diversos órganos jurisdiccionales, tanto Juzgados de lo Penal, Audiencias Provinciales, Tribunal Superior de Justicia, Audiencia Nacional y Tribunal Supremo. Por ello, este gráfico no muestra la tendencia de casos, sino la tendencia en los pronunciamientos judiciales, es decir, la actividad judicial en el marco temporal referenciado.
} 


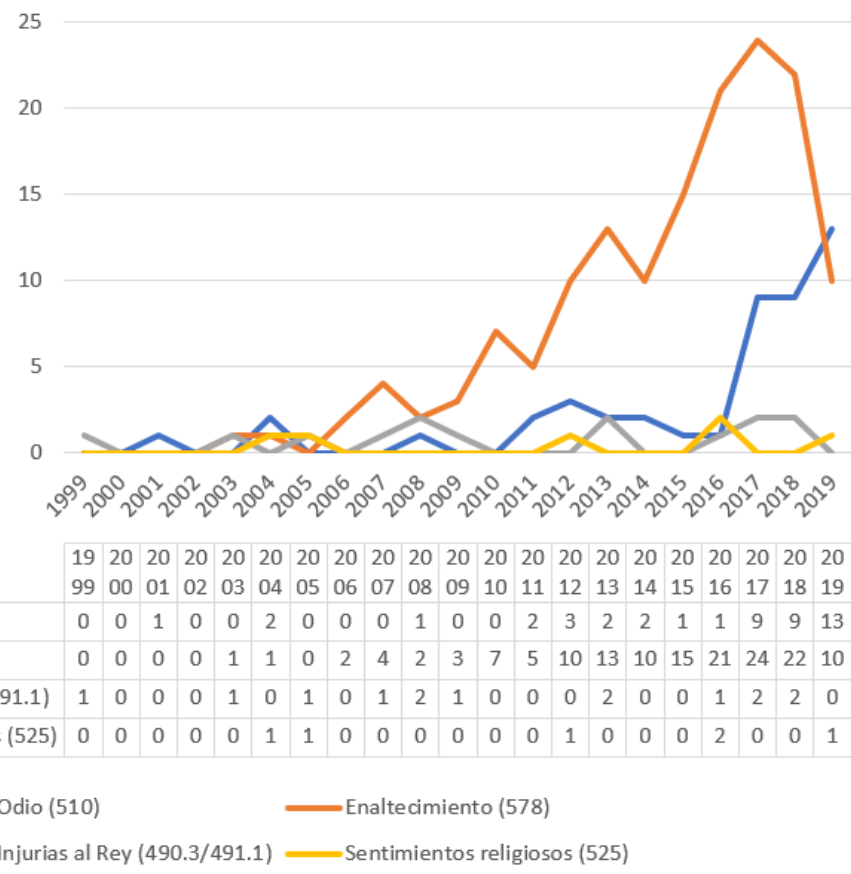

Gráfico 1. Gráfico descriptivo de la tendencia de las resoluciones judiciales por año. Elaboración propia

La tendencia de crecimiento es significativa en ambos delitos, aunque como se verá mucho más en el de enaltecimiento al que prestaré aquí más atención. En cuanto al delito del art. 510 CP, de la muestra analizada, entre 1999 y 2010 tenemos un total de 4 procesos que pasan a 10 en los años 2011 a 2016 incluídos y a 19 en los años 2017, 2018 y 2019. Desconociendo el total de casos enjuiciados no es posible saber si la tendencia que se intuye es general, pero parece difícil, dada la aleatoriedad en la selección de las sentencias, que no se corresponda efectivamente con un impacto de las redes sociales en la interpretación de un tipo penal cuya modificación entró precisamente en vigor en 2015.

Me ocuparé algo más del análisis de la tendencia de la aplicación judicial del delito de enaltecimiento del terrorismo ${ }^{25}$. Por un lado, si tenemos en cuenta únicamente las sentencias de la Audiencia Nacional se puede observar en el Gráfico 2 que, durante los primeros diez años de vigencia del tipo penal, el número de resoluciones judiciales no es especialmente alarmante en términos cuantitativos, y, en su mayoría tienen que ver con conductas enaltecedoras llevadas a cabo en el espacio físico y relacionadas con expresiones en manifestaciones, declaraciones parlamentarias, pancartas, folletos o fiestas populares o expresiones realizadas con ocasión del fallecimiento y entierro de

\footnotetext{
${ }^{25}$ Un análisis más detallado se ha realizado en Miró-LLinAREs, F., y GómEZ-Bellví́s, A. B., "Freedom of expression...", ob. cit.
} 
simpatizantes e integrantes de la banda terrorista ETA $^{26}$. Sin embargo, y más allá de las interpretaciones dogmáticas y jurisprudenciales que merezca la aplicación de este tipo penal durante esos años, lo que realmente ha venido preocupando en términos de libertad de expresión ha sido la proliferación de las sentencias contra expresiones emitidas en redes sociales y que han sido calificadas de enaltecimiento del terrorismo o humillación a sus víctimas hasta fechas recientes ${ }^{27}$, pese a que tales expresiones se producen en un contexto social en el que las bandas terroristas sobre las que versan las mismas, GRAPO y ETA, están felizmente desaparecidas. Si bien ya se contaba con algunas sentencias que enjuician las expresiones realizadas a través de Internet ${ }^{28}$, no es hasta 2014 cuando empiezan a aumentar, aunque moderadamente, las sentencias en las que se enjuician expresiones realizadas principalmente a través de redes sociales como Youtube, Facebook o Twitter ${ }^{29}$, y alcanzando un elevado número de resoluciones entre el periodo temporal que se comprende entre 2016 y 2020, hasta el punto de que la tendencia se invierte completamente entre el primer tramo de tiempo (2005-2010) donde las expresiones enaltecedoras se llevaban a cabo eminentemente en el espacio físico y eran pocos los supuestos y, el último tramo donde la gran mayoría de supuestos se llevan a cabo a través de Internet y las redes sociales, siendo asimismo el tramo que acumula un importante número de sentencias. Esta tendencia podría ser indicativa del impacto de las redes sociales en la restricción de la libertad de expresión. Podría interpretarse en el sentido de que Internet y las redes sociales han incrementado la realización de delitos de expresión. Es posible que haya sido así, pero desconocemos cuántos de quienes ahora tuitean antes no decían en otros ámbitos lo que pensaban. Lo que sí parece razonable es entender que lo que haya aumentado con la aparición de las redes sociales sea el potencial

\footnotetext{
${ }^{26}$ Es el caso, por ejemplo, de las: STSJ del País Vasco de 5 de septiembre de 2003; STSJ del País Vasco de 31 de marzo de 2004; SAN núm. 31/2006, de 26 de abril; STS núm. 585/2007, de 20 de junio; SAN núm. 67/2007, de 12 de noviembre; SAN núm. 49/2008, de 29 de julio; STS núm. 539/2008, de 23 de septiembre; SAN núm. 28/2009, de 21 de mayo; STS núm. 676/2009, de 5 de junio; SAN núm. 64/2009, de 16 de diciembre; SAN núm. 1/2010, de 19 de enero; SAN núm. 13/2010, de 2 de marzo; SAN núm. 224/"010, de 3 de marzo; SAN núm. 54/2010, de 9 de diciembre, entre muchas otras.

27 En este sentido, véase Gómez Martín, V., "Odio en la red. Una revisión crítica de la reciente jurisprudencia sobre Ciberterrorismo y Ciberodio", en Revista de Derecho Penal y Criminología, núm. 20, 2018.

${ }^{28}$ SAN núm. 62/2006, de 21 de noviembre que se corresponde con la absolución de los integrantes del grupo musical Sociedad Alkoholika por sus canciones subidas a una web; la SAN núm. 4/”010, de 2 de marzo que enjuicia las expresiones realizadas en foros de Internet; la SAN núm. 2/2012, de 17 de enero que enjuicia determinados comentarios en la red social Tuenti o la SAN núm. 11/2012, de 29 de febrero que enjuicia mensajes contra una europarlamentaria a través de Internet.

${ }^{29}$ Es el caso de: SAN núm. 8/2014, de 31 de marzo; SAN núm. 24/2014, de 19 de mayo; SAN núm. 13/2015, de 20 de mayo; SAN núm. 14/2015, de 25 de mayo; SAN núm. 37/2015, de 12 de junio; SAN núm. 39/2015, de 14 de octubre; SAN núm. 56/2015, de 16 de octubre; SAN núm. 32/2015, de 23 de noviembre.
} 
carácter público de lo expresado, la mayor exposición de las opiniones y, a partir de lo anterior, el incremento del control por parte de los órganos de investigación, como sucedió probablemente con la puesta en marcha de las conocidas "operaciones araña".

Resulta arriesgado, sin disponer de todas las resoluciones o del número que representan las de esta muestra sobre el total, poder determinar si además del crecimiento en los procesos también hay un crecimiento, proporcional, en las condenas. Esto es, afirmar si a partir de 2014 se ha condenado más por este delito. Lo que no es nada arriesgado afirmar es que desde este año hay muchas más personas condenadas por este delito que en el periodo anterior de su vigencia. Si atendemos únicamente a aquellas sentencias que han enjuiciado expresiones realizadas a través de Internet y de las redes sociales, en el Gráfico 3 podemos observar cómo la tendencia de la Audiencia Nacional sobre este delito es la de condenar ${ }^{30}$.

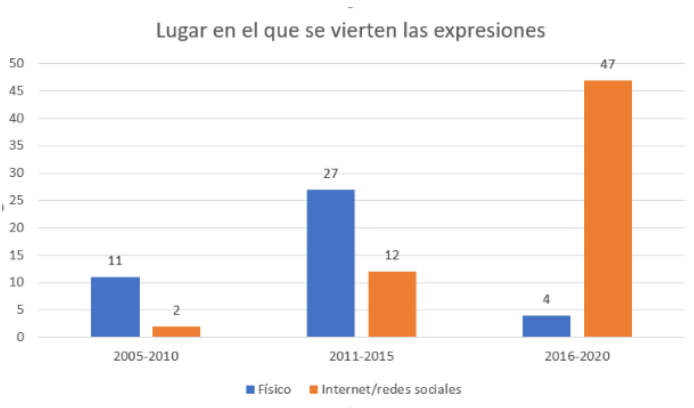

Gráfico 2. Gráfico descriptivo del número de sentencias según en lugar en el que se cometen. Elaboración propia

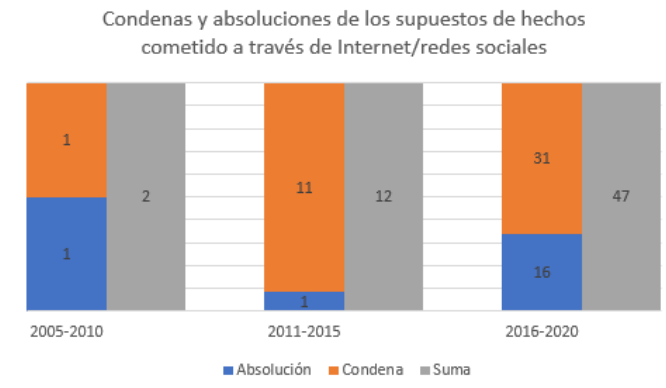

Gráfico 3. Gráfico descriptivo de las condenas y absoluciones de aquellos supuestos de hechos realizados a través de Internet/redes sociales. Elaboración propia

Se trata de la condena de expresiones mucho más cercanas a "lo ofensivo" que a lo lesivo como "España es nuestra rutina, golpear y quemar España nuestra rutina; la lucha es el único camino" 31; "Aupa esa chavalería que ha arrasado con las sucursales capitalistas de medida de ciudad de Bilbao. Joder, con noticias así da gusto empezar la semana" ${ }^{32}$; refiriéndose a la madre de una víctima de ETA “qué se puede esperar de una mala madre que hace negocio apoyando la impunidad de los asesinos de su hijo?"33; o, "SOS ETA; 1,

\footnotetext{
${ }^{30}$ Se han utilizado para los Gráficos 2 y 3 , únicamente las sentencias de la Audiencia Nacional para expresar la tendencia y no analizar los casos en particular. En este sentido, es necesario tener en cuenta que algunos supuestos en los que la Audiencia Nacional ha condenado por este delito, posteriormente han recibido la absolución por parte del Tribunal Supremo, como en el caso de Cassandra Vera.

${ }^{31}$ SAN núm. 3/2016, de 23 de febrero.

${ }^{32}$ SAN núm. 4/2016, de 1 de marzo

${ }^{33}$ SAN núm. 25/2017, de 4 de diciembre
} 
2, 3, patito inglés, sin mover las manos ni los pies. Irene Villa atrás; Necesito un sello de Carrero Blanco, primer astronauta español y lo necesito para ayer" ${ }^{34}$. Para las condenas, se suele tener en cuenta la propia actividad en la red social como el número de twitts ofensivos en particular y, en general el propio número de twitts de la cuenta, el número de seguidores ${ }^{35}$, el carácter abierto de la cuenta del usuario ${ }^{36}$ y del que se presupone el plus de peligrosidad de la expresión ${ }^{37}$, y por supuesto, la concurrencia de los elementos típicos que dan lugar al injusto. Así, se ha venido entendiendo que los elementos típicos del enaltecimiento del terrorismo son: “a) La existencia de unas acciones o palabras por las que se enaltece o justifica. Enaltecer equivale a ensalzar o hacer elogios, alabar cualidades o méritos de alguien o de algo. Aparece emparentado, pero tiene un significado más amplio, con el concepto de apología del párrafo II del artículo 18.1 CP. Justificar quiere aquí decir que se hace aparecer como acciones lícitas y legítimas aquello que sólo es un comportamiento criminal; b) El objetivo de tal ensalzamiento o justificación debe serlo respecto de las conductas terroristas o de cualquiera de las personas que hayan participado en la ejecución, no siendo necesario identificar a una o varias de tales personas; c) debe realizarse por cualquier medio de expresión pública o difusión" 38 . Por lo que se refiere a la tipicidad subjetiva, no se ha venido exigiendo ningún ánimo de realmente provocar a la violencia sino simplemente el dolo, entendido como conocimiento y voluntad sobre lo que se está expresando, es decir, conocimiento y voluntad de los elementos del tipo ${ }^{39}$. De esta forma, si en las expresiones emitidas se podían apreciar estos elementos del tipo, sin perjuicio de si realmente se estuviese enalteciendo en el sentido de llamar a la violencia y crear un peligro jurídicamente desaprobado aunque abstracto para un bien jurídico concreto, ni tampoco del conocimiento y voluntad de la creación de dicho riesgo, la condena estaba prácticamente

\footnotetext{
${ }^{34}$ SAN núm. 3/2018, de 15 de enero

35 SAN núm. 9/2017, de 29 de marzo; SAN núm. 4/2018, de 18 de enero

${ }^{36}$ SAN núm. 18/2017, de 21 de julio

37 SAN 14/2015, de 25 de mayo: "Hoy en día el cambio social viene ligado a la evolución tecnológica. Internet ha supuesto una revolución en el mundo de las comunicaciones y del conocimiento, con la particularidad de que permite a los países atrasados avanzar enormemente, pero también esta importancia de las redes sociales tiene su incidencia en el sistema penal, cualquier política criminal hoy día no puede ignorar esta explosión tecnológica que permite divulgar cualquier mensaje en pocos segundos a una multitud de usuarios situados en países lejanos con lo que se obtiene una publicidad de los mensajes impensable hace unos años".

38 STS núm. 149/2007, de 26 de febrero entre otras.

${ }^{39}$ STS núm. 948/2016, de 15 de diciembre: "Este Tribunal ha manifestado en resoluciones precedentes que los elementos subjetivos de los tipos penales se acreditan mediante juicios de inferencia pueden considerarse como hechos psíquicos insertables en la narración fáctica de la sentencia. Se afirma que los elementos subjetivos deben deducirse de datos externos y objetivos que constan en su relato fáctico"; SAN núm. 5/2018, de 18 de enero.
} 
asegurada. No obstante, resulta importante tener en cuenta que, tal y como se ha analizado en otro lugar ${ }^{40}$, las condenas por este tipo de expresiones dejan de ser casi automáticas ante la concurrencia de los elementos señalados frente a un nuevo giro argumentativo de la propia Audiencia Nacional y el Tribunal Supremo en sus más recientes resoluciones y en las que aplicando la interpretación del artículo 578 del Código Penal por parte del Tribunal Constitucional en la STC 112/2016, de 20 de junio, opta por absolver, al exigir ahora una situación de riesgo para personas o derechos de terceros derivado de una incitación aunque sea indirecta, como venía exigiéndose por la normativa internacional y el propio Tribunal Europeo de Derechos Humanos.

\section{III. ¿ESPERAR A UN POSIBLE EFECTO STRAWBERRY O} ANTICIPARNOS CON LA REFORMA PENAL?

Es difícil defender que España es un país en el que no existe la libertad de expresión, tanto como creer que las noticias respecto a la judicialización de decenas de personas no hayan creado en la ciudadanía una percepción de que se puede acabar implicado en un proceso penal, incluso condenado penalmente, por expresar ideas políticas especialmente radicales y transgresoras. No se ha cuantificado esa percepción subjetiva, ni sabemos si la misma ha impactado de algún modo en una tendencia de las personas a autocensurarse. Desde hace años se utiliza la expresión chilling effect, traducible a mi parecer como el efecto autocensura o efecto silencio ${ }^{41}$, para referirse al riesgo de que la prohibición de determinados tipos de discurso, especialmente la criminalización del discurso del odio, pueda impactar en la libertad de expresión llevando a que no sólo se omita la expresión de ese discurso sino también otros cercanos a él pero que no debieran prohibirse. Sin entrar en consideraciones imposibles aquí, pero bien tratadas en otros lugares ${ }^{42}$, respecto al modelo de democracia que tenemos y que debiéramos tener y, en relación con esto, a qué tipos de discurso político puede prohibirse, es indiscutible que la ambigüedad

\footnotetext{
${ }^{40}$ Miró-Llinares. F., y GómeZ-Bellvís, A. B., "Freedom of expression...,", ob. Cit.

${ }^{41}$ La mayoría de la doctrina lo ha traducido como efecto desaliento. Véase DE DOMINGo PÉREZ, T., "La argumentación jurídica en el ámbito de los derechos fundamentales en torno al denominado "chilling effect" o "efecto desaliento", en Revista de Estudios Políticos, núm. 122, 2003; DE DOMINGO PÉREZ, T., "La lucha contra el 'discurso del odio' desde el respeto a los derechos fundamentales", en MIRó LLINARES, F. (Dir.), Cometer delitos..., ob. cit.; CUERDA ARNAU, M. L., "Proporcionalidad penal y libertad de expresión: la función dogmática del efecto de desaliento", en Revista General de Derecho Penal, núm. 8, 2007. Creo que es menos expresivo de lo que queremos medir en futuros trabajos que los términos, efecto silencio, o autocensura, que utilizaré indistintamente.

${ }^{42}$ Presno Linera, M. Á., y Teruel LozAno, G. M., La libertad de expresión...,ob. cit.
} 
valorativa inherente a estos discursos puede producir el citado efecto de que, buscando prohibir algo, se acabe silenciando mucho más. Y más si, como sabemos, el ámbito público en el que se expresan las opiniones políticas en la actualidad está sujeto a la decisión de entes privados que establecen reglas similares a las que limitan la expresión en el ámbito penal, pero aún de forma más restrictiva; por lo que los propios usuarios que quieran ser altavoz público pueden autocensurarse antes de acabar fuera de los "community standards". Todo esto lo intuimos pero no lo sabemos. En el otro trabajo citado me he acercado de forma empírica a estas cuestiones para poder tener algo más de certeza al respecto ${ }^{43}$.

Lo que sí sabemos, a partir del análisis de sentencias aquí realizado, es que en España la popularización de las redes sociales convirtió un delito que apenas se había aplicado en una fuente de procedimientos e imputaciones penales significativa. También que la interpretación judicial de los tipos penales ante las primeras ofensas en 140 caracteres fue más expansiva y amplia, a mi juicio demasiado, que la que ha ido siendo después. Asimismo, parece que esta tendencia ha empezado a cambiar gracias a la STC 112/2016, de 20 de junio y, posiblemente seguirá cambiando a propósito de la reciente sentencia del Tribunal Constitucional sobre el caso de César Strawberry y que anula la sentencia condenatoria del Tribunal Supremo, al entender que el Alto Tribunal no había tenido en cuenta la intencionalidad de crítica política de estas expresiones, tal y como ya señalé en otro lugar ${ }^{44}$. Puede ser que con la publicidad y cobertura mediática que recibirá esta anulación y amparo constitucional se produzca el "efecto Strawberry", una creencia de que ahora se puede afirmar todo en redes sociales siempre que sea dentro de la crítica política o ideológica, o simplemente el efecto de creer que en un país democrático como el nuestro nadie va a ser condenado por defender hasta las ideas más abyectas. En cualquier caso, habría que medir ese efecto y trataremos de hacerlo, ya que no parece que el legislador vaya a optar por la profundamente necesaria y solicitada reforma de los delitos de expresión en términos de volver a la criminalización de aquellas expresiones realmente lesivas ( $u$ ofensivas en el sentido restrictivo que he defendido y que deja fuera cualquier forma de crítica política ${ }^{45}$ ), solicitando, por tanto, la derogación de la mayoría

\footnotetext{
${ }^{43}$ Miró-Linares, F., y GómEZ-Bellvís, A. B., "Freedom of expression...”, ob. Cit.

${ }^{44}$ Miró LlinARES, F., "Derecho Penal y 140 caracteres. Hacia una exégesis restrictiva de los delitos de expresión”, en Miró LlinARES, F. (DIR.), Cometer delitos..., ob. cit.

${ }^{45}$ Ibid.
} 
de conductas incluidas en los anteriores preceptos penales que no han tenido ni tienen un debido encaje en los principios de un Derecho Penal propio de una sociedad democrática ${ }^{46}$.

${ }^{46}$ Grupo de Estudios de Política Criminal, Una propuesta alternativa de regulación de los delitos de expresión, Tirant lo Blanch, Valencia, 2019. 